\title{
FUNCTIONS, FUNCTIONING AND OPTIMIZED POSITIONING OF PRESSURE CONTROL VALVES IN OIL-HYDRAULIC CIRCUITS
}

\author{
M. N. E. Reis ${ }^{a}$, \\ S. G. Tavares ${ }^{\mathrm{a}}$, \\ C. B. Soares ${ }^{b}$, \\ J. A. Soares ${ }^{\text {c }}$, \\ R. H. R. Antunes ${ }^{c}$, \\ C. H. L. Fossa ${ }^{c}$, \\ P. R. Monteiro ${ }^{\mathrm{d}}$, \\ ${ }^{\text {aa }}$ Departamento de Engenharia da Pontifícia \\ Universidade Católica de Minas Gerais \\ Av. Dom José Gaspar, 500 \\ Coração Eucarístico \\ Belo Horizonte - MG - Brasil \\ 30535-610 \\ mara@pucminas.br \\ gtavar@terra.com.br \\ ${ }^{\mathrm{b}}$ Centro Federal de Educação Tecnológica de \\ Minas Gerais - Av. Amazonas, 5253 \\ Nova Suiça - Belo Horizonte - MG - Brasil \\ CEP 30480-000 \\ cleide.barbosa@ig.com.br \\ ${ }^{\mathrm{c}}$ Estudante de Engenharia de Controle e \\ Automação ${ }^{d}$ Estudante de Engenharia \\ Mecânica da Pontifícia Universidade \\ Católica de Minas Gerais - Av.Dom José \\ Gaspar, 500 - Coração \\ Eucarístico - Belo Horizonte - MG - Brasil \\ 30535-610 \\ joaosoares@yahoo.com.br \\ richard_henrique@yahoo.com.br \\ cal_bhz@yahoo.com.br \\ paulo.monteiro@uol.com.br
}

\section{ABSTRACT}

The pressure control valves can perform different functions in the hydraulic systems, such as: establish maximum pressure, reduce pressure in some circuit lines, and establish sequence movements, among other functions. The main operation of these valves consists of providing a balance between pressure and the force load on a spring. Most of these valves can be positioned in many different levels, between totally open and totally closed, depending on the flow and on the pressure differential. The pressure control valves are usually named according to their primary functions, e.g., lock wire valve, sequence valve, safety valve, etc. and, their basic function is limit or to determine the pressure of the hydraulic system for the attainment of a certain function of the equipment in motion. They are also classified by the type of connections, by the size and by the selected pressure band. Instead of relief and security, discharge, counterbalance, sequence, reducing and shock suppressor valves represent the pressure control devices. In this paper, oil-hydraulic circuits are suggested for practical lessons of Hydraulic and Pneumatic Commands where they regulate valves of pressure, by acting in the following situations: limiting the maximum pressure of the system, determining a level of pressure, determining two different levels of pressure, determining at the same time two distinct levels of pressure, unloading the pump. The functions of these devices will be discussed and analyzed as an attempt to improve their position in the circuit.

Keywords: pressure regulating valves, circuits, oil-hydraulics, practical lessons of Laboratory of Hydraulic and Pneumatic Commands.

\section{INTRODUCTION}

So that a hydraulic system can operate, some elements are required, which, by limiting, reducing, regulating or interrupting the pressure, will enable the sequential control of some pre-determined or instantaneous operations.

The pressure regulating valves have the main function of limiting or determining the pressure of the hydraulic system so that the equipment in motion is able to perform a certain function. They work in any of the five following situations:

Limiting the maximum pressure of the system: all of the systems possessing a pump of fixed displacement need a safety valve. When a pump demands fluid for a cylinder and this arrives at the end of the course, the pressure goes up to a maximum level causing damage to the system. Thus, the 
limitation of the pressure, through pressure regulation, is decisive in this kind of circuit.

Determining the level of work pressure: In some systems the relief is just a factor of safety, in others, it is a component of the work control. The pressure regulation keeps the pressure of the system at a uniform level, sometimes diverting to the tank part of all fluid supplied for the pump at certain moments of the operation cycle. It controls the force or maximum torque of the actuators, protecting the equipment or parts of it forms damage.

Determining two different levels of pressure: Some systems need high pressures at some stages of the work cycle and lower at others. This can be foreseen in the use of the regulating pressure.

Determining at the same time two distinct levels of pressure: A regulator of the relief type determines the high pressure and a reduced low pressure. One can be adjusted differently from the other without affecting each other, depending on the position that they take in the hydraulic system.

Unloading the pump: Sometimes, some circuits do not need all of the supplied power in some specific phases of the cycle. In general, this can be averted with the convenient adjustment of excessive power.

\section{PRESSURE REGULATION IN HYDRAULIC SYSTEMS}

Pressure in the hydraulic systems is regulated by means of valves, most of which of infinite positioning, meaning that they can take different positions, ranging from totally open to totally closed, depending on the flow and the differences in pressure. The complete domain of its functioning principles will bring significant benefits and will optimize the good use of these in different industrial applications.

According to their construction principle, the pressure regulating valves can be:

Of direct operation: They are used for light flow and they actuate quickly.

They have low sensitivity and precision, becoming vulnerable to alterations after adjusted. This type of valve is very used in 'mobile' drive commands.

Of indirect operation: They are used for heavier flows and the regulation precision is higher than the previous type; for this reason they are the most widely used in industrial hydraulic circuits. The work pressure of the hydraulic system acts against a blocking element (Poppet) that is pressed against the seat of the valve by a spring; when the pressure of the system is lower than the force of the spring; the poppet moves away from its seat deviating the excessive flow from the tank, protecting the system from overpressure. The most well known pressure control devices are:

Relief and security valves;

Discharge valves;
Counterbalance valves;

Sequence Valves;

Reducer valves.

\section{FUNCTION, FUNCTIONING POSITIONING OF THE REGULATING PRESSURE VALVES IN OIL - HYDRAULIC CIRCUITS}

\section{Relief and Security Valves}

Relief and security valves are present in almost all hydraulic systems.

They are normally closed, located between the pressure line (pump outlet) and the reservoir.

The relief and security valves perform two functions in a hydraulic circuit: they limit the pressure in the circuit or in part of it, in the preselected level, and protect the system and the different equipment that protect it from overload.

The relief and security valves can be of three types: of pilot-operated direct operation, indirect and differential.

\section{Direct Operation Relief and Security Valves}

Consists basically of a body with two openings: a fluid inlet under pressure and an outlet for the reservoir.

As shown in Fig. 1 inside the body there is a mounted sphere or poppet kept against the seat for spring effect, whose tension is regulated by a screw.

The pressure in the system is applied directly on the part of the sphere or poppet. This sphere or poppet is kept in the seat to propel the action of the spring. When the pressure surmounts the action of the spring, the sphere or poppet moves away from the seat allowing the fluid to escape to the reservoir, thus minimizing pressure.

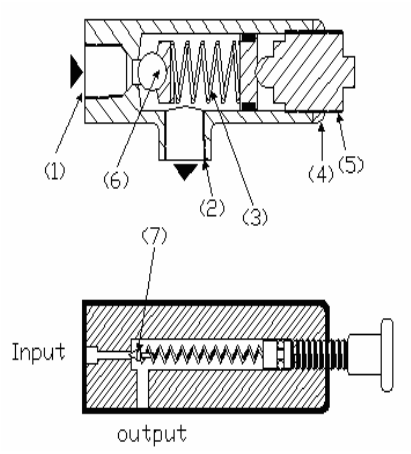

Figure 1. Direct operation valve of relief. (1)Fluid inlet on pressure. (2) Fluid outlet for the reservoir. (3)

Spring. (4) Lock nut. (5) Regulation screw. (6) Sphere. (7) Poppet.

If the pressure continues to go up, the spring is compressed and moves away even further from the 
sphere or poppet and as a result a heavier fluid flow returns to the reservoir. The higher the pressure, the more compressed the spring, keeping for itself a directly proportional relation, reaching a maximum value, at which all the flow of the pump is diverted to the tank.

Although some fluid flow is diverted to the reservoir, the pressure of the system remains constant, because if somehow it decreases to a level below the minimal pressure of the opening, the spring immediately pushes the sphere or poppet against the seat, blocking the passage again.

The pressure at which the valve starts to open is called cracking pressure. The pressure at which all the flow of the pump is deviated to the tank is called full flow pressure, higher than the cracking pressure. After the flow is relieved, the valve must again be turned off and a new cycle starts; the pressure must fall to a level lower than the cracking pressure, as the tendency of the oil is to continue to flow (equation of Bernoulli); this pressure is named reseating pressure.

If the cracking pressure is around $50 \%$ to $60 \%$ of the full flow pressure, during the interval between these two pressures, the system loses in efficiency and suffers a loss of power, which is transformed into heat.

Utilization: The use of direct action relief valves is limited, because they prevent the necessary pressure regulation, and do not possess good repeatability and stability, which means that a valve like this, regulated for 70 bar, can open at a very different pressure loads from this regulated value.

Where it can be used: For systems of low power and low flow, direct-operated relief and security valves are the best choice due to their cost. For more powerful systems it is only recommended for "stand by" operations, to foresee the security of the circuit.

This valve can also be used to control the pilot of an indirectly-operated relief valve (remote control). In the same way, they are used in wind lines, where, like in the pilot lines, the flow is lower.

Where it cannot be used: Some types of directly operated relief valves emit a low noise during some flows and pressures. This noise is the result of an internal vibration or fluctuation of the sphere or poppet, which may damage them if the valves are in constant use for pump discharge.

Due to the big difference between the cracking pressure and the full flow pressure, the directly operated relief valve does not offer enough protection to the system if it is regulated to foresee a "bleed" operation (fluid bleeding or deviation line). If it is regulated for a lower pressure, the valve will compromise the speed and power of the actuators, and cause extreme heat generation.

For the limiter pressure valves of direct drive, it must also be observed that the pressure of the system modifies in accordance with the drained volume, independently of the programmed full flow pressure.

\section{Relief Valve and Differential Safety}

It's a direct relief variation whose purpose is to show the smaller area of the poppet and the action of the pressure on the system, enabling the use of weaker springs and smaller dimensions with better characteristics, which can improve the performance of the valve.

Fig. 2 shows this type of valve with a small differential piston possessing a neck at the central part and resilience at the bottom part.

The pilot stage in the upper body contains the limiter valve of pressure and a small piston is kept in the seat for an adjustable spring. The porches are found at the bottom part of the body, and flow diversion occurs due to the displacement of a balanced piston in this body.

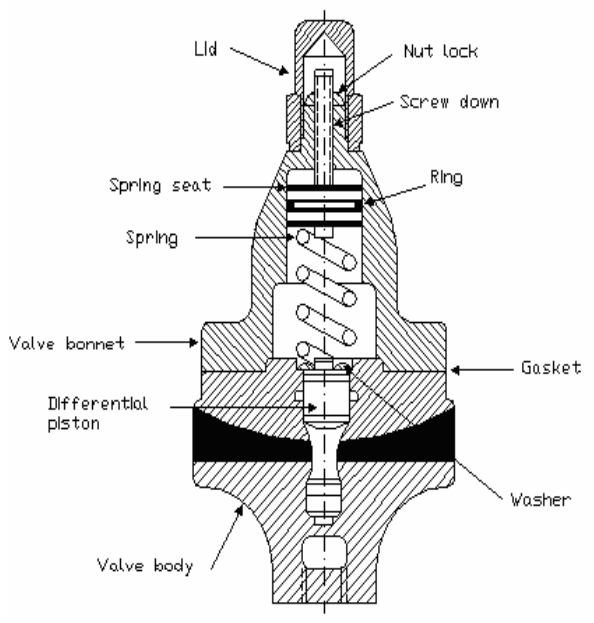

Figure 2. Section in the differential valve of relief.

The pressure of the system entering into either of the two sides will actuate in an annular area that is the result of the value of the area of the small piston subtracted by the area of resilience of the bottom part.

For the variation of the resilience diameter, the area effectively exposed to the pressure is varied, in accordance with what was desired. The pressure of the system surmounting the action of the spring, forces the set to dislocate to the point at which the oil is relieved to the tank.

When differential valves for high capacities of pressure and flow are needed, this type of valve is used.

\section{Indirectly-Operated Relief and Safety Valve}

They are also called pilot-operated relief and security valves. They are those in that one a directlyoperated valve commands the operation of a two-way directional valve.

The pilot valve triggers an impulse the sets the mail valve working. This device makes it possible for the valve to enter in operation many times per minute, opening and closing without damaging or 
wearing out the nesting cone. Additionally, the movement of the internal parts is slowed down rendering the operation smooth.

In Fig. 3, the pressure from the hydraulic system penetrates into the inlet pressure valve and actuates against the spool, positioned so that it blocks the oil passage to the tank. This same pressure will act against the directly-operated relief valve through the orifice in the spool. At the same time, this pressure will actuate on both sides of the spool that, having the same area, suffers identical forces in opposite directions. In that way, the "spool" stays balanced hydraulically and it is forced to occupy the position usually closed for effect of an existent spring in your upper part.

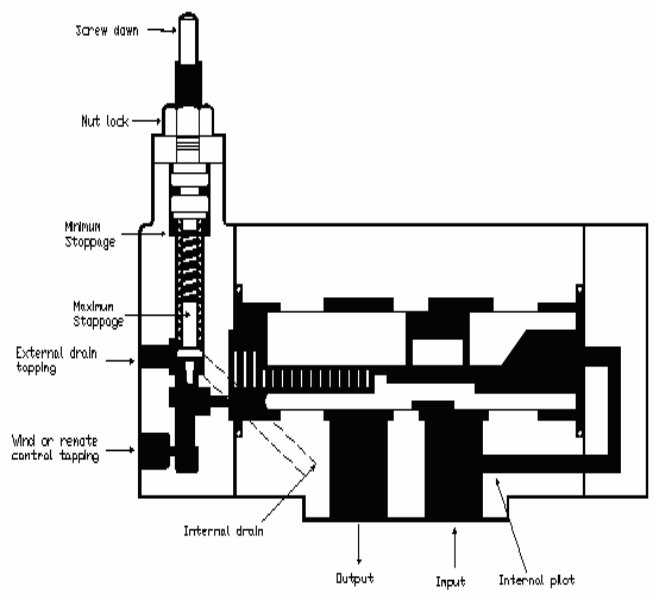

Figure 3. Section in pilot-operated valve of relief.

The pressure in the opening is regulated in the directly-operated relief valve, modifying the tension applied to the spring through the regulation screw. When the pressure reaches the selected value, it pushes the poppet away from the seat and a small amount of oil starts to flow through the valve and through the internal drain down the wall of the discharge, into the reservoir.

The chamber above the spool tends to empty itself and initiate a fluid flow at a very high speed through the orifice. This flow leads to a loss of load through the orifice, causing a differential between both faces of the spool.

This differential displaces the spool upwards, connecting the inlet of pressure and the discharge for the tank, thus allowing the pressure of the system to be relieved.

The existing filter in the spool is an accessory that stops any impurity from obstructing the orifice, which would compromise the performance of the valve.

The indirectly-operated relief and safety valve can allow the passage of heavier flows, because the flow that crosses the duct pilot for the opening of the valve is very small, compared with the total flow of the system.

\section{Counterbalance Valve}

It is used to support the force impelled on the hydraulic actuator by the load that is being transported / dislocated (induced pressure).

It is generally not desired that a set hydraulic element initiates its movement before a positive action is applied to it, fluid on pressure. For example, a case of high pressure can be mentioned in which the punching equipment must be kept in the upper position during the retreat of the part at work and fed with new raw material.

Falls due to the effect of gravity force must be prevented, Fig. 4.

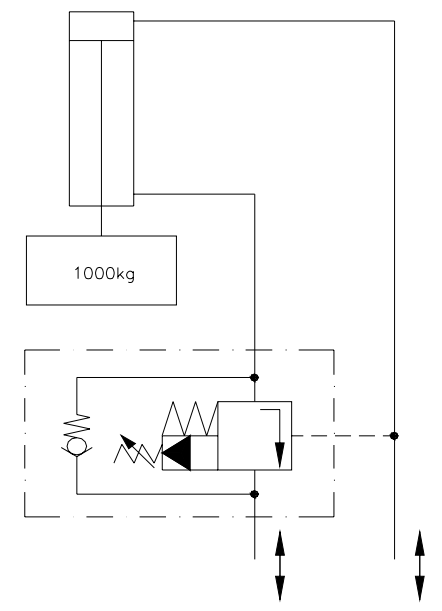

Figure 4. Example of application of the valve of counterbalance.

The regulation of this valve must be a little bit higher than the necessary pressure to retain the load

This function is performed by the counterbalance valves, either of direct or remote command (internal or external pilot).

It is a sequence valve that is mounted inversely, that is, the sequence valve when open allows the oil to flow into the actuator while the counterbalance valve expels the oil through the outlet in the actuator; therefore, it is also possible to get a counterbalance valve from a relief valve.

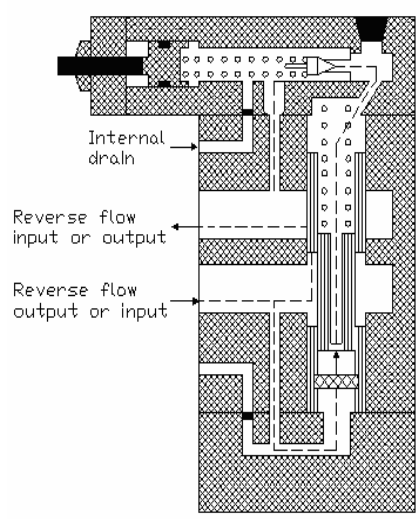

Figure 5. Section in valve of counterbalance. 
The counterbalance valve is nothing more than another version of the indirectly-operated relief and discharge valves, as shown in the Fig. 5. It generally incorporated with a valve of integral retention to allow free reverse flow.

The pilot can be internal or external, the ideal being the external, and the drain can also be internal or external (in case no resistance against the flow sequence occurs, after the counterbalance valve is directed to the tank, it must be preferred to the internal drain).

\section{Discharge Valve}

It is used to unload part of the hydraulic system at a lower pressure than that adjusted for the relief valve.

The functioning principle is nothing more than another version of the relief valve, however, the pilot is external, and the drain can also be internal, Fig. 6 .

The constructive difference between the discharge valve and the relief valve lies in the inclusion of a piston of external pilotage with an area $15 \%$ bigger than the main poppet; or else, the discharge valve can be made from a relief valve.

Example of application: in circuits of high/low pressure/flow, circuits with accumulators, circuits with pump of radial pistons with division of the flow of the pistons, and others.

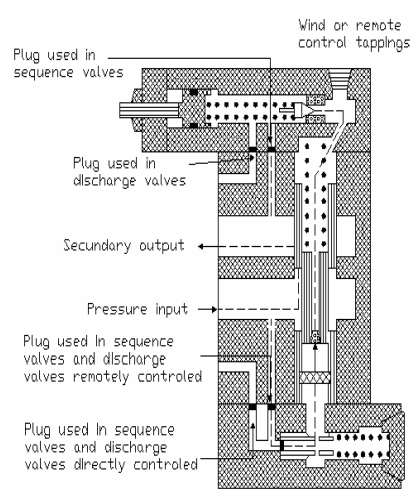

Figure 6. Section in valve of discharge.

In Fig. 7, there is a hydraulic circuit where a high speed and low pressure cylinder must be dislocated until it reaches the work point where low speed and high pressure are demanded. For this reason, two pumps are used; one of fixed displacement working at low pressure and high flow, and another one of variable displacement with compensation of pressure working at high pressure and low flow.

In the hydraulic circuit of the Fig.8, called "High and low pressure of Circuit "or "High and Low flow", the desired course of action is for the approach of the cylinder to be fast and the execution of the work to be slow; however, at full load.

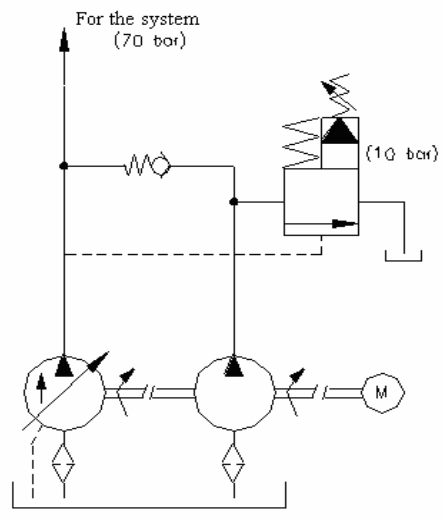

Figure 7. Application valve of discharge.

When the cycle is initiated, the two pumps supply heavy flow into the cylinder that advances at high speed and null force. When the cylinder starts to perform the work properly, the pressure of the system increases and through the pilot duct the discharge valve is opened, diverting all of the flow of the pump of fixed displacement to the tank, at the same time as the retention valve serves as protection for this pump, it prevents the flow of the other pump from going into the reservoir. In this way, the cylinder will advance, now, slower and at full load, therefore, only the pump of variable flow performs the work.

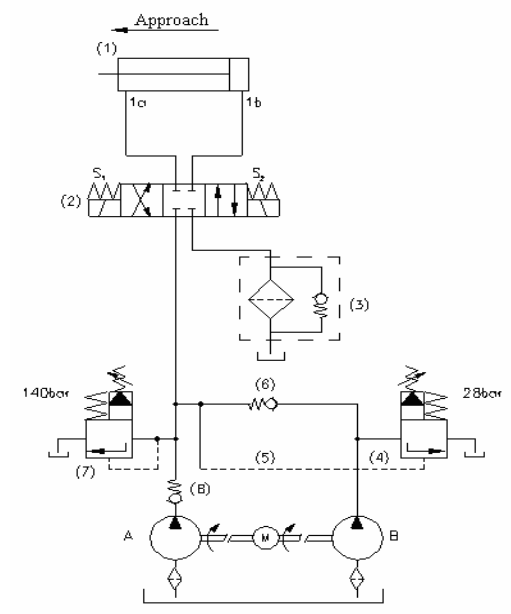

Figure 8. "High and Low Pressure of Circuits" or "High and Light Flow".

\section{Sequence Valves}

They are used in the hydraulic systems to determine a sequence of steps in the process or sequence of movements between two actuators. The sequence valve is used in a system to activate the actuators in a certain order, and to keep a predetermined minimum pressure in the inlet line during the secondary operation.

Principle of functioning: the fluid reaches the connection of inlet of the valve that is blocked to the outlet: the actuator is set, it is connected to the tube system, which is connected to the inlet of the 
sequence valve (before entering it); when this stage is concluded the pressure of the line increases until it attains the force of the regulate spring, thus opening the passage to the outlet connection. In the opposite way the flow passes through a simple retention valve (by pass), Fig. 9

It is also important to say that the pilot in the sequence valves can be of internal or external, in accordance with the type of system in use, however, the drain must be external and the value regulation will be minor than the value adjusted in the relief valve.

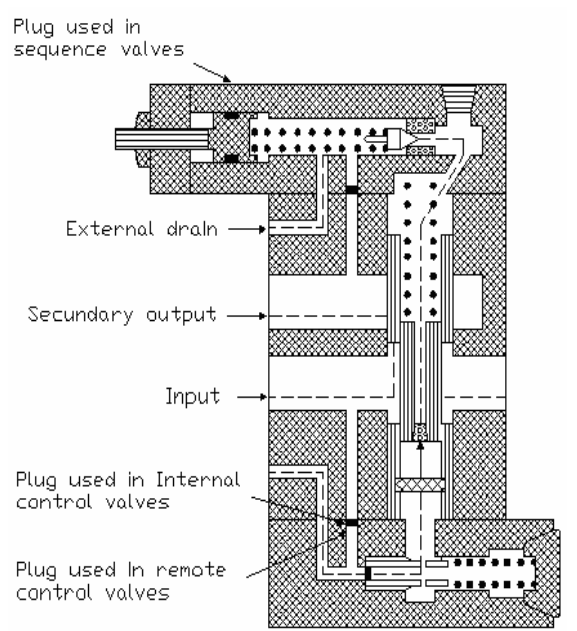

Figure 9. Section in valve of sequence.

A relief valve can be transformed into a sequence valve by observing the position of the drain, as well as the necessity of free return (bypass).

The relief and discharge valves, when open, dislocate the oil flow to the tank and the sequence valves to initialize the next stage of work.

In Fig. 10 the hydraulic circuit of presents two cylinders that will be moved by the same source of pressure. However, both in the advance and in the return, one of the cylinders must complete the work before the other initiates its work.

A way to obtain this and really guarantee that a cylinder reaches the end of its work course before the other initiates is by using sequence valves.

A typical application is to use the first phase for a blocking cylinder, and the second to control the movement of a drill after the piece has been firmly locked by the cylinder of the 1st operation.

In order to keep the pressure in the first phase, the valve is operated internally. However, the drain connection will be external because the secondary porch will be under pressure when the piston rises to perform the sequence of operations.

If this pressure could penetrate the drain passage, it would be added of the force of the spring, increasing the pressure necessary to open the valve.

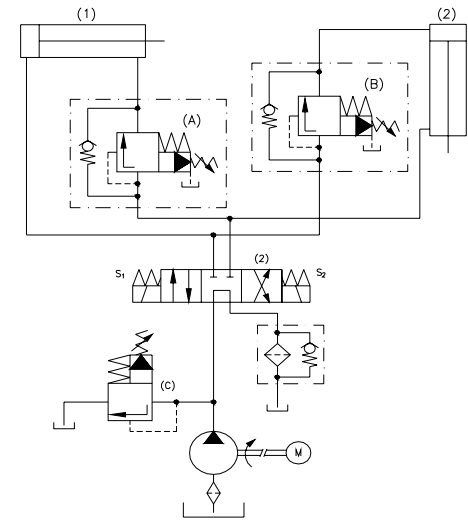

Figure 10. Sequential hydraulic circuit.

\section{Pressure-Reducing Valve}

In order to protect a circuit against overloads and limit the work pressure, valves of relief and security are used. However, many times, there are hydraulic circuits where diverse lines are fed by one same source, but it must work at different levels of pressure. For this reason, pressure-reducing valves are used.

Its functions are as follows: they reduce the pressure in some parts of the hydraulic circuit.

The pressure reducing valve can be obtained from a relief valve; it inverts the internal piston and changes the connections: the inlet becomes the outlet, and the outlet becomes the inlet; the pilotage continues at the same point and like in the sequence valves, the drain must be external, Fig. 11.

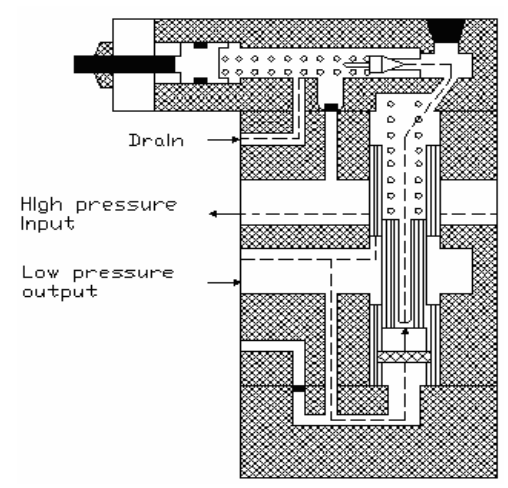

Figure 11. Section in pressure valve of reducing.

There are two basic differences between this valve and the previous one: the pressure-reducing valve is normally open; the pilot is in the outlet, while in the others the pilot is in the inlet.

The valves are actuated by the outlet pressure, which tends to close the valves when the effected adjustment is reached, thus preventing an undesirable pressure surge. The reducing valves can be of direct action or operated by pilot.

In Fig. 10, a reducing valve can be mounted just after the sequence valve (B) to ensure that the 
pressure supplied to the cylinder (2) never exceeds a selected level, which, if above the cylinder, would produce an extreme force compromising the wimble of the drill.

The Fig. 12 shows a hydraulic circuit with pressure regulation in the cylinder, with connection in sequence and dependence of the pressure for the advance and return of a cylinder.

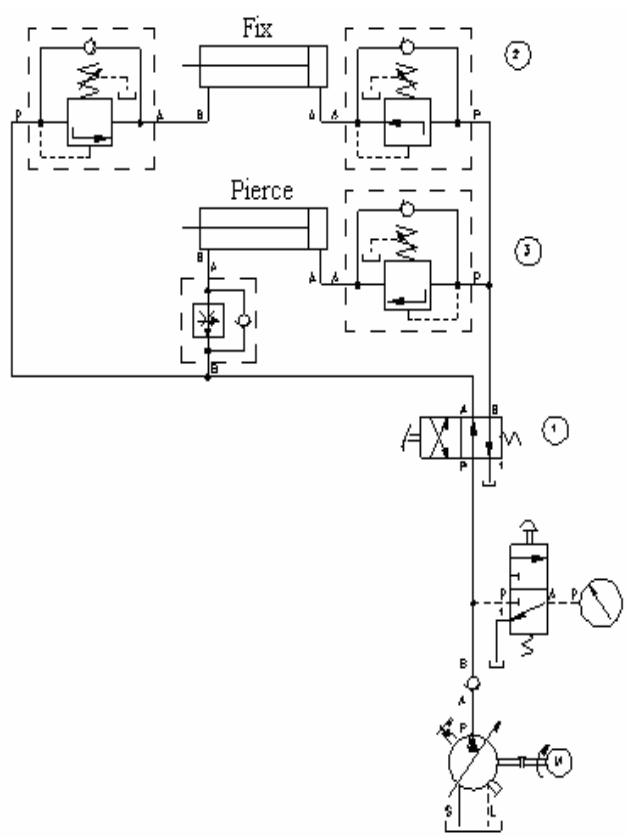

Figure 12. Hydraulic cylinder with pressure regulation in the cylinder.

\section{VENTAGE AND REMOTE CONTROL}

Ventage a hydraulic system means depressurizing it through a connection linked to the limiter pressure valve; an action which becomes necessary at the departure/stop position of the hydraulic pump, mainly in systems of average/high pressure, as well in those where these components function for a long time without effective work accomplishment.

With this, it revives the useful life of the pump with a significant reduction in the consumption of electric power, once departure/stopped peaks will be far smoother.

Ventage can be done manually, however, in industrial circuits it is produced by a solenoidoperated directional valve. Such valve can be mounted in the body of the main pressure regulating valve or separate from it, depending on its constructive principle, Fig. 13.

When it is in operation, the directional valve allows the passage of the flow, which will actuate on the regulation poppet, directly from the lowresistance tank to its displacement, thus on the side of the spring, the pressure falls and the main piston of the pressure limiter remains open by the action of the pressure in its the previous area (on the opposite side of the spring) due to the difference of pressure caused by the small passage orifice. While there is flow through of the directional valve, the regulating valve of pressure will be open.

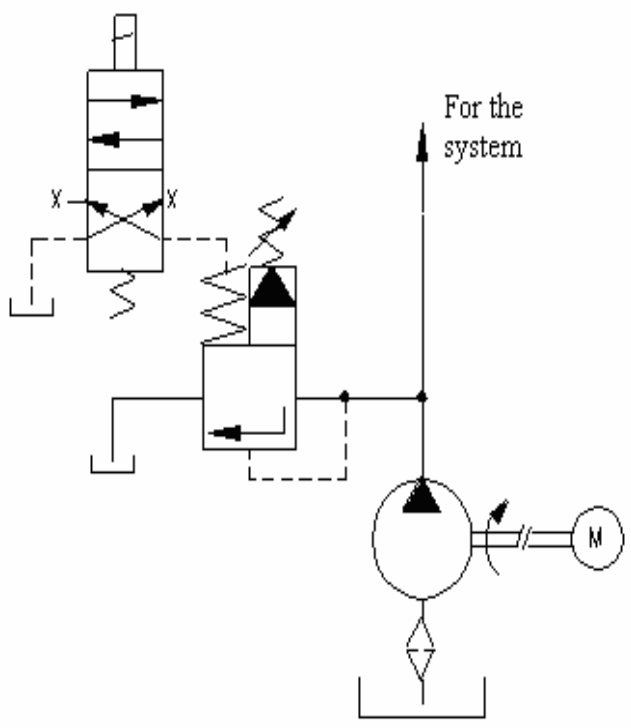

Figure 13. Pilot-operated valve of relief.

\section{Remote Control}

It is still possible to connect this regulating tapping of the main pressure to the other relief valve for pressure remote control Fig.14. The remote control will allow the control of a pressure regulating valve at a distant point from the place where it is mounted in the circuit, for example, next to the operator; it allows, in combination with the wind, the junction of the directional hydraulic controls to obtain diverse pressure values of indirect action (heavy flow). Both the directional valve and the others that regulate pressure can be of a small size, once the flow that will pass through them is inferior to the flow in the main pressure limiter valve.

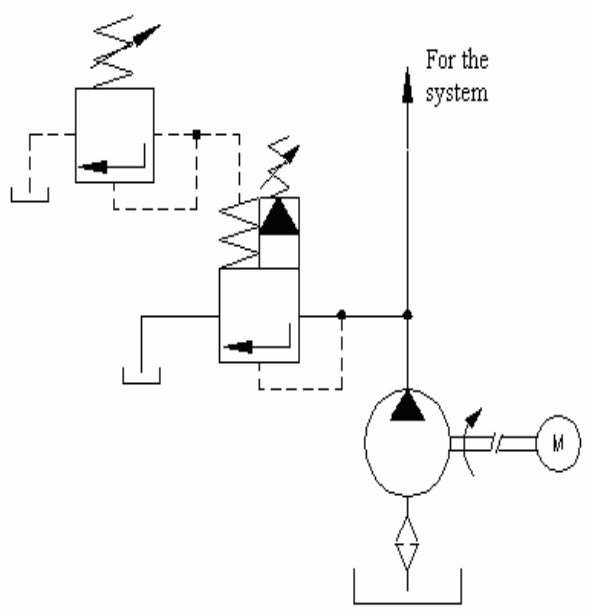

Figure 14. Remote control of the pilot-operated valve of relief (a two-pressure system). 
When a combination of directional valves and directly-operated relief valves is needed, getting any pressure desired will depend on the necessity of the machine, Fig. 15.

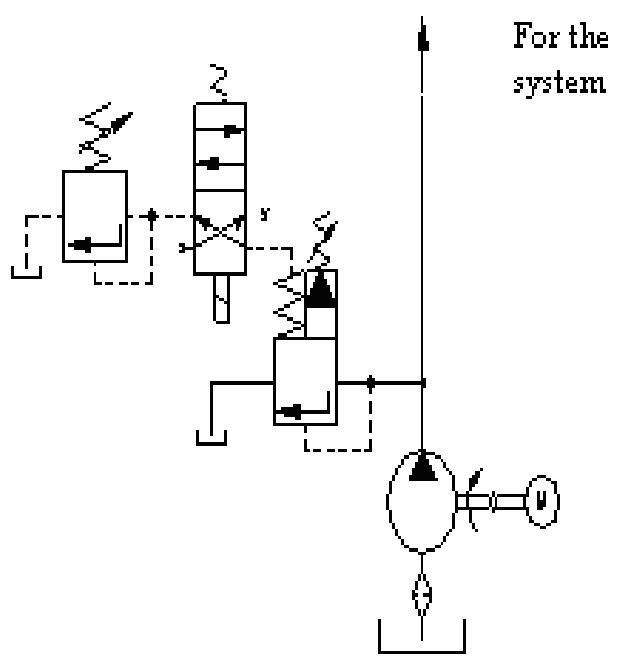

Figure 15. Combination of Ventage and Remote Control.

\section{CONCLUSION}

For a hydraulic system to operate, some elements are required, which by limiting, reducing, regulating or interrupting the pressure, will allow a control sequential of some pre-established or instantaneous operations.

The basic function of the pressure regulating valves is to limit or to determine the pressure of the hydraulic system through the modulation of the pressure for the attainment of a certain function to be performed by the equipment.

Pressure regulation in the hydraulic systems is performed by valves, most of which, of infinite positioning, or else, they can assume different positions from totally open to totally closed, depending on the flow and difference of pressure. These valves can be directly or indirectly operated.

The name of the pressure regulation generally describes the action in the hydraulic system. In practice, these controls are normally open or normally closed.

They can be externally or internally drained, depending on the characteristics of the action. Adjustment through the screw is the most common type. There are others such as: cams, pedals, handspikes etc.

The construction of pressure regulating valves can differ; however, the main operation will be always the same.

The most common problem in the operation of the pressure regulating valves lies in the piston (poppet) of command, which wears out, forming a ring-shaped mark in the point of contact with the seat.

Therefore, any pressure regulating valve can be gotten from the relief valve, by making small alterations. For that, it is just enough for the technician to have a slight knowledge of the subject and dedication to its maintenance in the productive processes.

The complete domain of operating principles will bring significant benefits and will optimize its use in diverse industrial applications.

\section{REFERENCES}

Associação Brasileira de Hidráulica e Pneumática, 1993, Coletânea de Artigos Técnicos, volume I e II.

Fialho, A. B., 2004, Automação Hidráulica, Projetos, Dimensionamento e Análise de Circuitos, Editora Érica, São Paulo, Brasil.

H511 - Introdução a Hidráulica, 1995, Festo Didactic, Brasil.

H521 - Técnicas, Aplicação e Montagem de Comandos Hidráulicos, 1987, Festo Didactic, Brasil.

Linsingen, I.V., 1989, Curso Sistemas Hidráulicos, Laboratório de Sistemas Hidráulicos e Pneumáticos, Universidade Federal de Santa Catarina, Florianópolis, Brasil.

Linsingen, I.V., 2003, Fundamentos de Sistemas Hidráulicos, Editora da UFSC, Florianópolis, Brasil.

Manual de Hidráulica Básica, 1989, Racine Albarus Hidráulica Ltda., pp. 153-170.

Hidráulica Básica, 1981, Rexroth Hidráulica Ltda., Vol. 1, pp. 111-123.

Manual de Hidráulica Industrial, 1986, Sperry Vickers, pp. 9.1-9.17.

Received: February 05, 2006

Revised: March 05, 2006

Accepted: April 05, 2006 